\title{
Rainfall-induced landslides in Quaternary soils in Norway
}

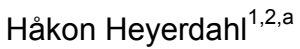 \\ ${ }^{1} \mathrm{PhD}$ student, University of Oslo, Norway \\ ${ }^{2}$ Norwegian Geotechnical Institute (NGI), Oslo, Norway
}

\begin{abstract}
Increased intensity of rainfall in later years seems to result in increased frequency of rainfall-induced landslides in natural slopes with glacial Quaternary deposits, which cover large parts of Norway. Many slides hit railway and road infrastructure, and sometimes dwellings. Typically, the soil matrix has a high content of intermediate soils (sand and silt). Natural soil slopes may have inclinations above the effective friction angle of the soils. Slope stability hence must rely on some cohesion, which often is "apparent", i.e. caused by negative pore-water pressure (suction). Dissipation of suction during short- or long-term rainfall hence results in reduced shear strength of the slope, and may lead to slope failure. There is a scarcity of data for Norwegian soils for thorough analysis of landslide triggering based on unsaturated geomechanics. More data may result in improved landslide warning. In this paper, results from unsaturated shear box testing of samples of a silty sand taken from a landslide site in Eastern Norway are presented and discussed.
\end{abstract}

\section{Introduction}

Soils encountered in Norway are predominantly of Quaternary origin. Marine clay and silt were deposited in the sea. The former seabed has later been lifted onshore by isostatic uplift when the glaciers covering Northern Europe gradually melted. Above the marine limit of today's landscape, other types of glacial sediments are encountered, primarily till and glacio-fluvial deposits, and to some extent glacio-lacustrine deposits. In addition to these two groups, post-glacial deposits of all varieties are encountered, like fluvial deposits, colluvium, scree/talus, landslide debris and sometimes eolic sediments.

\section{Landslide morphology}

Rainfall-induced landslides in Norway often occur in deposits where the soil matrix consists of intermediate soils (silt and sand). Above the marine limit, slides occur frequently in lateral moraine deposits on slopes of Ushaped valleys. Although the content of coarse material may be substantial in moraines, finer grains in the silt and sand fraction are abundant and generally govern the behaviour. Initial slides released by rainfall are often shallow or superficial with typical depths of 1-2 meters below the ground surface. Slides initiated on open slopes or along small creeks may quickly develop into highly mobile debris slides or debris flows due to high water content and erosion and entrainment along the morainecovered valley sides. The landslide debris may be very mobile, and runout often affects transportation

\footnotetext{
$\overline{{ }^{a} \text { Corresponding author: hhe@ngi.no }}$
}

infrastructure or buildings down-slope of the release zone, resulting in e.g. closed railroads and highways.

Sandy and silty slopes are vulnerable to subsequent erosion, if surface water finds its way into the landslide scar, and especially so if the vegetation cover first has been damaged or removed. Slides occur in fluvial, glacial, glacio-fluvial and glacio-lacustrine deposits with varying composition. Below the marine limit, rainfallinduced slides occur in marine silts, and to some extent also marine clays.

A study of meteorological conditions leading to the release of a high number of slides in primarily marine sediments in Eastern Norway during the autumn year 2000 indicated that long-term rainfall rather than intense scours was the primary landslide trigger [1].

Slides in coarser sediments, e.g. glacial deposits on steep valley sides, generally are released as the result of short-term rainfall with high intensity, or as a combination of short- and long-term rainfall. The critical intensity of infiltration for triggering of debris flows in glacial deposits has been observed to depend on duration of infiltration, i.e. combined effect of rainfall and snowmelt [2]. Release of slides in fine-grained soils generally requires prolonged rainfall, rather than shortterm intense scours.

The effect of the vegetation's root system on the soil stability should be considered and may be of substantial importance where the root zone goes down to some depth. The shear strength of roots is difficult to quantify, but advances are being made [3]. For grassy slopes, however, the root zone can be of limited thickness, maybe only a few centimeters or somewhat more (Figure 1 ), and critical failure planes may cut underneath it. 
Natural slopes are exposed to rainfall infiltration depending on the climatic conditions of the region where the slope is located. Slopes will eventually find a geometry somewhat in balance with the local climatic and hydrological conditions. Alternatively, if the slope is not in balance with the prevailing climatic/hydrologic conditions, the slope will be subject to continuous processes as erosion and landslides.

Both for glacial and non-glacial sediments, natural deposits may form natural slopes that may be very steep. In areas with glacio-lacustrine silt, vertical soil slopes of tenths of meters are encountered. Such slopes may keep stable as long as the slope surface is protected towards direct infiltration from rainfall, and suction may continue to keep the slope stable without dissipating. When extreme rainfall occasionally hits such a slope, the result may be that the slope surface fails.

Suction is assumed to contribute in keeping many steep natural slopes stable, but the role of unsaturated geomechanics for a wide range of Norwegian soil types has not been investigated extensively. In the following sections, data from laboratory testing of a sand from Eastern Norway is presented.

\section{Landslide site}

Samples of a silty sand for laboratory testing were collected manually at a landslide site at the farm Negarden Sander in the municipality of Eidsvoll, Eastern Norway (Figure 1). The foundations of the nearest building were almost undermined, but the building was saved due to repair works of the landslide scar (Figure 1).

Unsaturated shear box tests were performed on intact specimens from sample Sand A1 (Table 1).

Table 1. Sand sample. Fractions of sand, silt and clay.

\begin{tabular}{|l|c|c|c|c|c|}
\hline Sample & Depth & Sand & Silt & Clay & $\mathbf{C}_{\mathbf{u}}$ \\
\hline ID & $\mathrm{m}$ & $\%$ & $\%$ & $\%$ & - \\
\hline Sand A1 & $0.55-0.80$ & 71 & $\sim 27$ & $\sim 2$ & 3.1 \\
\hline
\end{tabular}

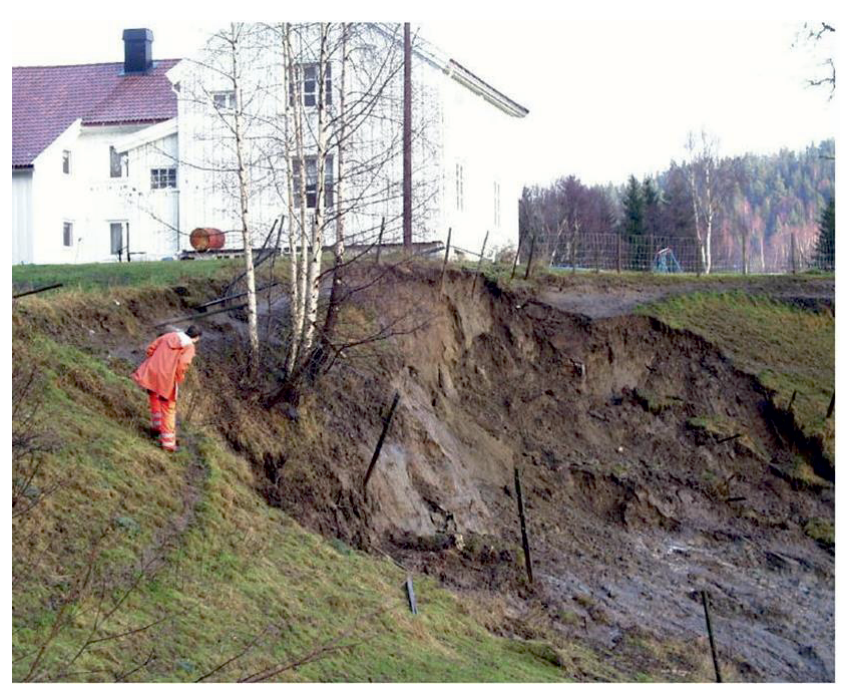

Figure 1. Landslide in sand and silt, Negarden Sander, Eidsvoll in Eastern Norway in the autumn of year 2000. Seepage of ground water visible from the foot of the landslide scarp.
The samples were brought to Barcelona for testing in the geotechnical laboratory at the Catalonian Technical University (UPC).

The landslide was released in the unusually rainy autumn of year 2000 [1] in a slope consisting of $5 \mathrm{~m}$ layered sand and silt overlying a thick marine clay deposit. The landslide is typical of many landslides in the region, often released in silty and sandy deposits. The landslide debris was highly mobile (Figure 2).

Main soil layering consists of silty sand and sandy silt layers down to $5 \mathrm{~m}$, followed by a thick deposit of marine clay to large depth. Ground water level is assumed to lie at approx. $5 \mathrm{~m}$ depth, i.e. at the top of the clay layer (Figure 1). The top section down to $1.5 \mathrm{~m}$ depth was inspected from an excavated pit. Main layers are described as follows: Silty sand above $0.8 \mathrm{~m}$ and below $1.3 \mathrm{~m}$ depth, a clay lens from 0.8 to $1.0 \mathrm{~m}$ and sandy silt between 1.0-1.3 m (Figure 3).

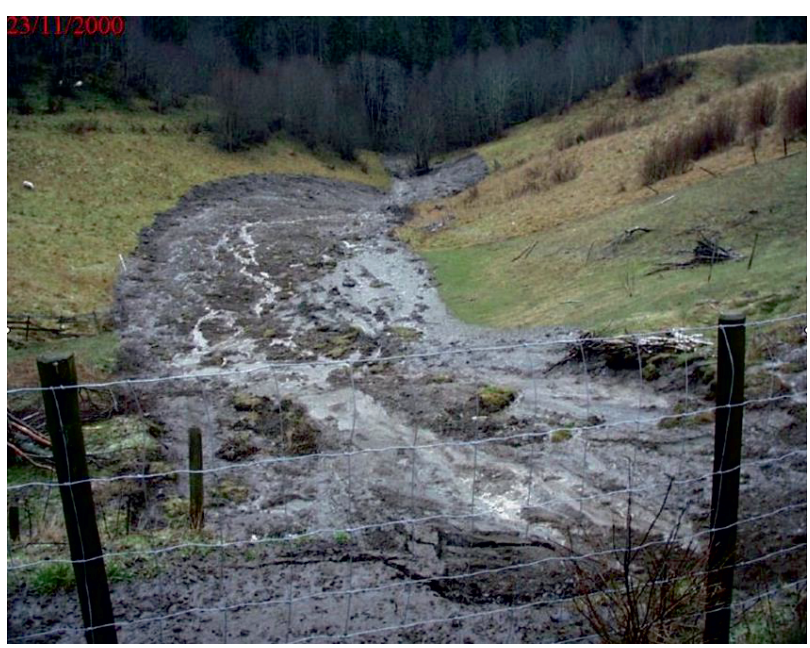

Figure 2. Highly mobile runout from landslide in silty sand at Negarden Sander, Eidsvoll in Eastern Norway, in the autumn of year 2000 .

In situ tensiometer measurements down to $1.2 \mathrm{~m}$ at the time of soil sampling confirmed that suction up to approx. $25 \mathrm{kPa}$ was present in the soil (Figure 3), in the order of $10 \mathrm{kPa}$ in the sand specimens tested (depth 0.6 $0.7 \mathrm{~m}$ ), and just below $25 \mathrm{kPa}$ in the silt layer.

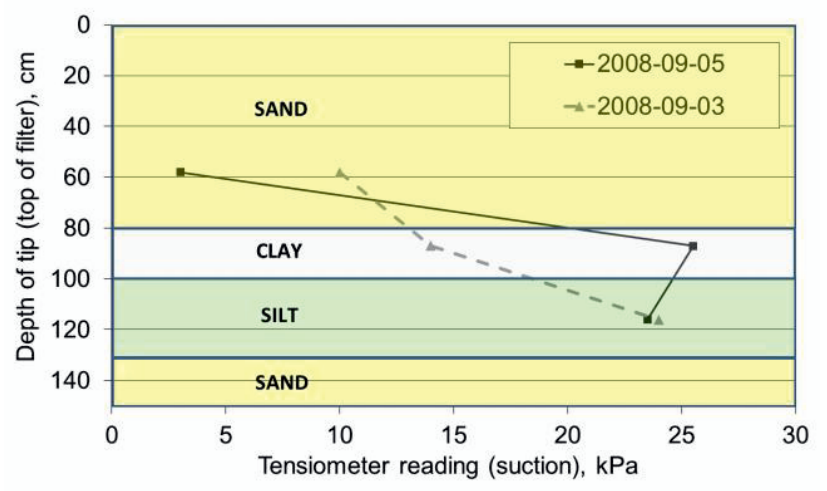

Figure 3. Measurement of suction during soil sampling.

A rainfall on the day prior to sampling had significant effect on the suction profile. Reduced suction in the sand layer indicates increased saturation due to infiltration of water in the upper part of the profile. However, suction in 
the clay layer increased in the same period, indicating some time lag. For the deepest tensiometer, no significant suction change was measured. The tensiometer tip was positioned in the silt layer below the clay layer. Infiltration in this layer may be prevented by the cap layer of less permeable clay, and suction remains almost unchanged after the rainfall (Figure 3).

\section{Retention curve}

The retention curve of the sand was measured combining several laboratory test methods: grain size distribution, high capacity tensiometer, mercury intrusion porosimetry, psychrometer and negative water column [4]. The main drying branch of the retention curve is presented in Figure 4. The air entry value is $5 \mathrm{kPa}$, and the residual water content is $3.35 \%$ (for suction $27 \mathrm{kPa}$ ).

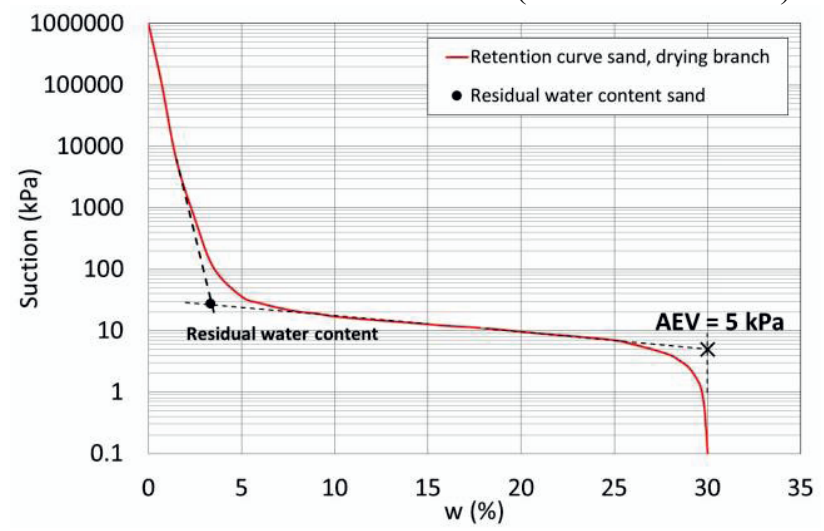

Figure 4. Retention curve for sand (drying branch) [4]. Suction versus gravimetric water content.

\section{Shear tests}

Results from two multi-stage unsaturated shear box tests on intact sand specimens are presented in the following. The tests were performed using an unsaturated shear box at the geotechnical laboratory at UPC, Barcelona. The tests were performed as an introductory part of a test program, primarily focussing on unsaturated shear strength of silt sediments [5], and do not give a complete picture of the unsaturated strength of the sand layer. However, the data still give some indications of interesting features for the unsaturated strength of sand.

The shear box apparatus is similar to the one described in [6], however instead of one pressure chamber, the apparatus has one upper and one lower pressure chamber. Pressure in the upper chamber is used to control vertical load. The shear box is placed inside the lower pressure chamber on top of a porous disk with air entry value $500 \mathrm{kPa}$. A water outlet exits from the underside of the disk. The water outlet may be connected to a GDS pump in order to control matric suction by axis translation, in combination with controlled air pressure in the lower test chamber. Volume of water in and out of the specimen is found by monitoring volume change with time in the GDS pump. Air diffusion through the porous disk will affect the total volume change. The rate of air diffusion through the disk was measured together with the water permeability of the disk in a separate test
(Figure 5). When the added water has flowed through the porous disk, the volume change continues at a lower rate, representing air diffusion. From the rate of air diffusion, net water flow during a test can be computed from measured total volume change in the GDS pump, excluding the volume related to air diffusion.

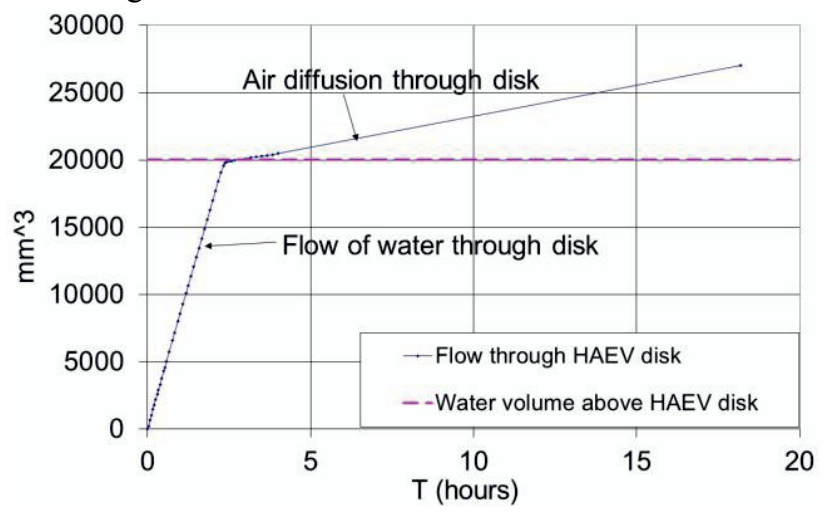

Figure 5. Measurement of water permeability and air diffusivity through porous disk of unsaturated shear box apparatus.

Test conditions and horizontal displacement rates during shear tests are given in Figure 6 and Table 2. In test Sand S2, vertical net stress was changed from step to step while suction was kept constant. Suction was controlled by the axis translation technique [7]. In test Sand S3, the specimen was saturated prior to the shear test. The saturated test was performed with water inside the test chamber. In the next test step, suction was applied by use of negative water column: A water-filled tube was connected to the water outlet from the water compartment below the high air entry value disk, which is used to control suction when applying axis translation. Suction was established by allowing the tube to suck water from the specimen from one day to the next, before shearing the specimen.

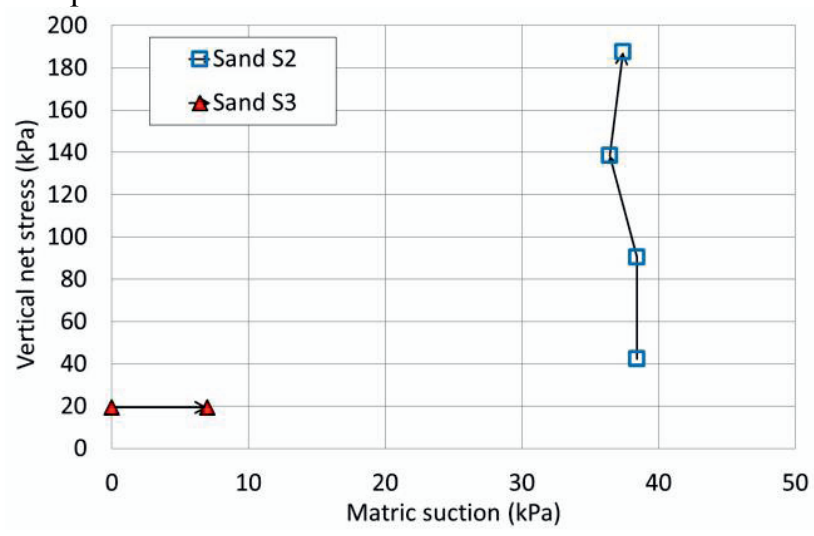

Figure 6. Load paths for unsaturated shear tests. Arrow tips indicate last load stage in each test.

Table 2. Unsaturated shear tests on sand.

\begin{tabular}{|l|l|l|l|}
\hline Test & Depth & $\begin{array}{l}\text { Initial } \\
\text { condition }\end{array}$ & $\begin{array}{l}\text { Displacement } \\
\text { rate }\end{array}$ \\
\hline ID & $\mathrm{m}$ & - & $\mathrm{mm} / \mathrm{min}$ \\
\hline Sand S2 & 0.62 & $w_{\text {in situ }}$ & 0.005 \\
\hline Sand S3 & 0.66 & $w_{\text {saturated }}$ & 0.015 \\
\hline
\end{tabular}


The measured peak shear stress in test Sand S2 increases for increased vertical net stress (Figure 7). The vertical compression is positive throughout all test steps. Applied vertical net stress in test Sand S2 is higher than in situ stress, which makes compression expected.

Test Sand S3 is performed at vertical net stress only slightly higher than estimated in situ stress. The behaviour is still compressive during the shear phase (Figure 8). Peak shear stress increased from the first to the second load step, when suction was applied. Because the shear box had to be disassembled to remove water between the two load steps of test Sand S3, the track of total displacements was lost. For total displacements it was assumed elastic unloading/reloading cycle between the two load steps (Figure 8).

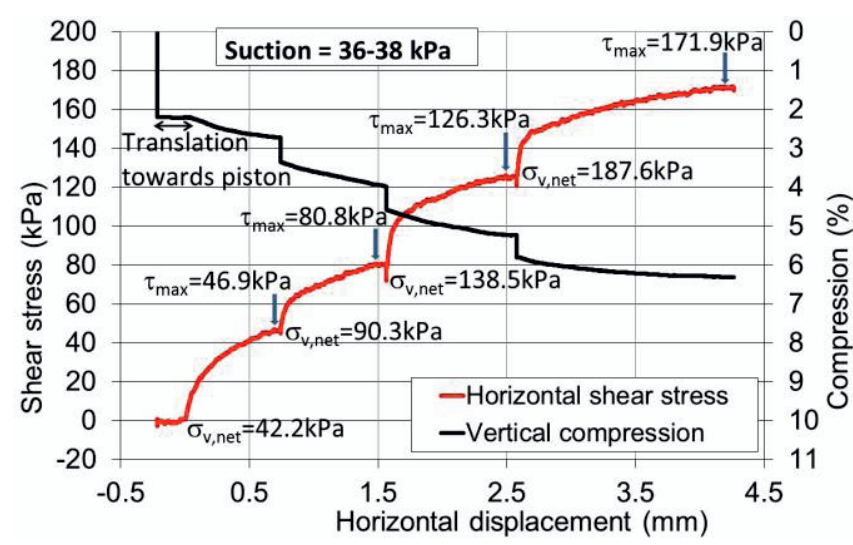

Figure 7. Shear test Sand S2, shear stress versus horizontal displacement. Four load steps increasing vertical net stress at approx. constant matric suction $(36-38 \mathrm{kPa})$.

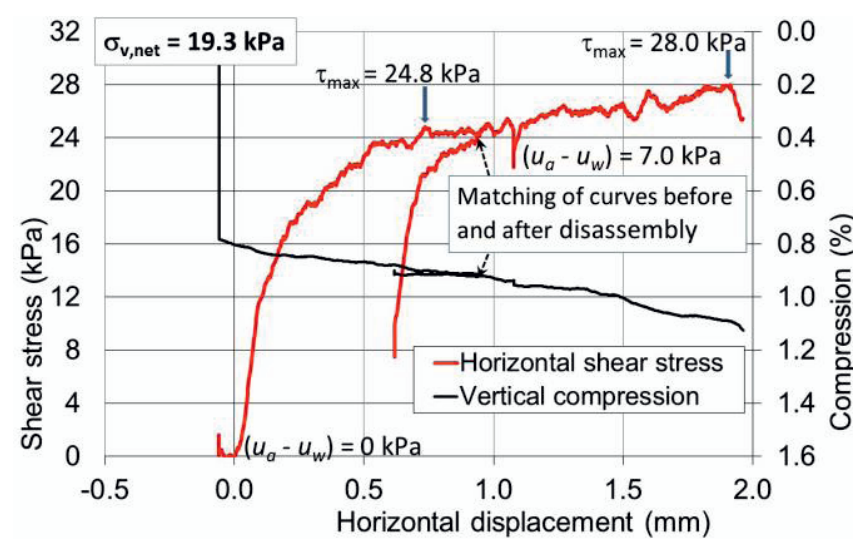

Figure 8. Shear test Sand S3, shear stress versus horizontal displacement. Two load steps, starting with saturated specimen. Approx. constant vertical net stress $(19.3 \mathrm{kPa})$.

Measured peak shear stress was plotted versus vertical net stress (Figure 9) and suction (Figure 10), respectively. Shear tests were performed at different levels of applied vertical net stress (Figure 6). Peak shear stress values presented in Figure 9 and Figure 10 may therefore not be compared directly, since shear strength varies with both vertical net stress and matric suction. To isolate effect of suction on shear strength, measured peak shear stress values were translated to the zero vertical net stress plane [8] using the effective friction angle, $\varphi^{\prime}=41^{\circ}$, interpreted from test Sand S2 (Figure 9). An effective cohesion $c^{\prime}$ of $8 \mathrm{kPa}$ was interpreted from the saturated load step of test
Sand S3 (Figure 11). The second load step of test Sand $\mathrm{S} 3$ shows a substantial increase in shear strength when a suction of $7 \mathrm{kPa}$ is applied, with approx. $40 \%$ higher peak shear stress than in the saturated load step.

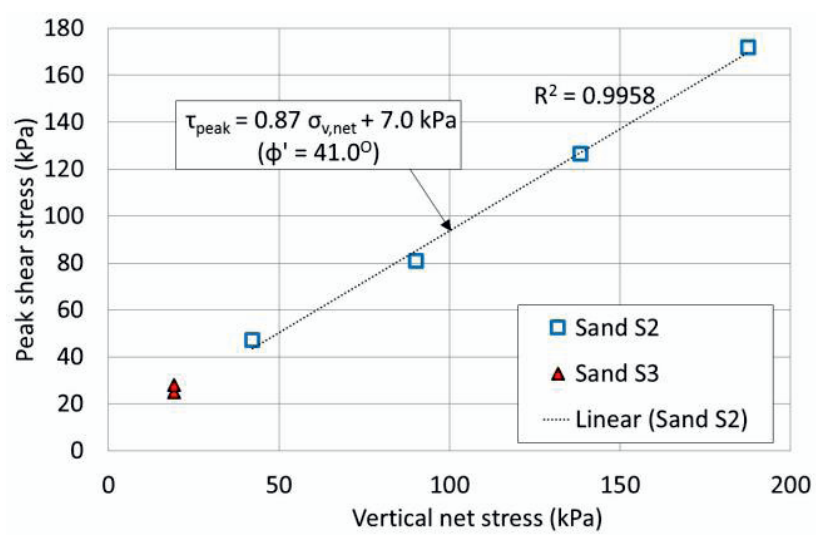

Figure 9. Peak shear stress versus vertical net stress for shear tests on sand.

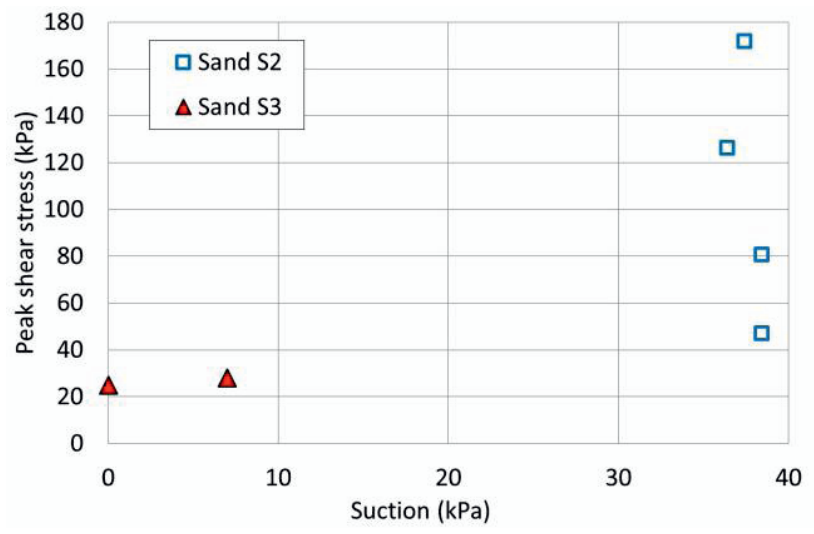

Figure 10. Peak shear stress versus matric suction for shear tests on sand.

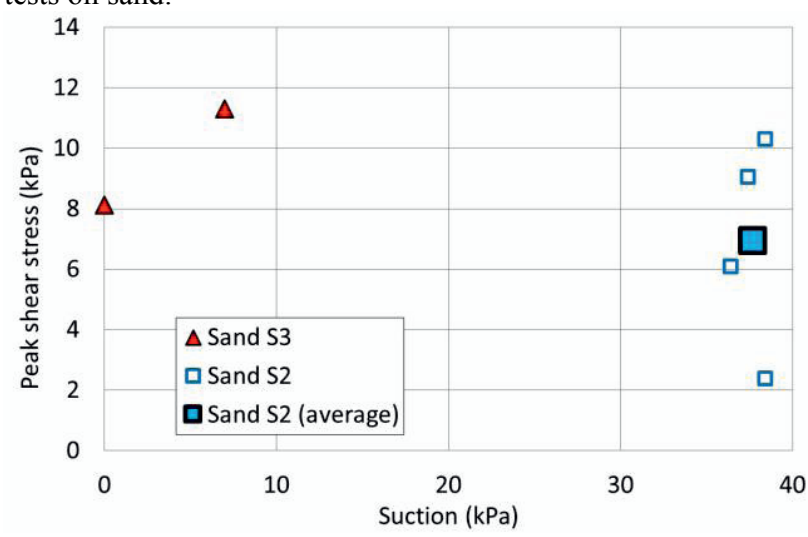

Figure 11. Peak shear stress versus matric suction from shear tests on sand, translated to zero vertical net stress. Average value of four measured values from test $\mathrm{S} 2$ is shown.

For test Sand S2, translation of comparatively large vertical net stress values to the zero vertical net stress plane results in some data spread, because the relationship between peak shear stress and vertical net stress is not completely linear (Figure 9). As a result, the back-calculated peak shear stress values for zero vertical net stress are not equal, although applied suction is the same $(+/-1 \mathrm{kPa})$ for the four data points. The mean value of the four data points from test Sand S2 is approx. $7 \mathrm{kPa}$ (Figure 11), indicating that the effect of increased suction is small (or even negative) when compared to measured 
peak shear stress in test Sand S3. Similar observations of decreased unsaturated shear strength above some limiting suction in fact was observed already in early unsaturated research on sand [9].

\section{Odometer test}

The relatively high effective cohesion (for a sand) found from shear test Sand S3 (Figure 11) could be related to over-consolidation and mechanical interlocking of grains. A conventional odometer test with incremental stepwise loading was performed on an intact sand specimen (Table 3). In situ vertical stress is estimated to approx. $5 \mathrm{kPa}$. The results may indicate that the soil actually is overconsolidated (Figure 12). For comparison, vertical strains from consolidation steps of shear tests Sand S2 and Sand S3 (values from before shearing) are also included in Figure 12. However, care should be taken with respect to interpretation of overconsolidation from odometer tests on sand.

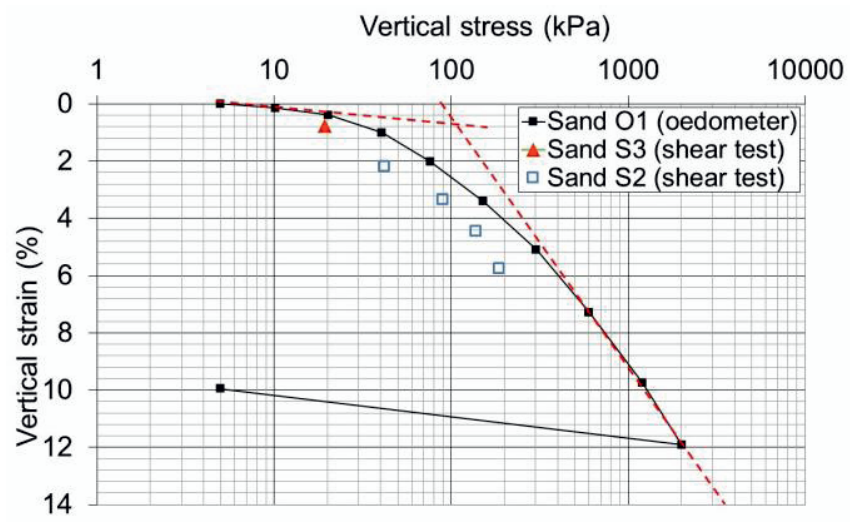

Figure 12. Saturated odometer test O1. Vertical strain versus vertical stress at end of step (logarithmic $1^{\text {st }}$ axis). Also shown: Vertical strain at end of consolidation from shear tests Sand S2 and Sand S3 (vertical strain before shearing).

No notable wetting collapse (volume reduction) was observed during initial saturation of the initially unsaturated odometer specimen. Since vertical net stress was low $(<1 \mathrm{kPa})$ in the specimen during saturation, collapse during wetting would expectedly be moderate, compared with saturation performed at a larger vertical net stress [10]. On the other hand, the sand has already experienced a large number of wetting and drying cycles in situ, due to the climatic setting and small in situ depth (0.2-0.3 m), and thereby expectedly less prone to wetting collapse. Suction stress resulting from drying could also result in over-consolidation [11].

Two important differences could be found from a comparison of the observed behaviour of these intact soil specimens with the collapsing behaviour of loess sediments experiencing wetting: Firstly, loess deposits are extremely well sorted materials, which may be deposited as metastable structure relying on capillary suction in menisci to keep stable (and sometimes some cementation). The soil skeleton will collapse when the stabilizing forces from the menisci at the grain contacts disappear during wetting. Secondly, the climate under which such eolic sediments are often encountered, e.g. in north-central China, however is very dry, which will keep the sediments stable and prevent sliding [12], except for during extreme rainfall events.

\section{Predicted unsaturated shear strength}

The unsaturated strength $\tau_{f}$ was predicted from the two commonly used unsaturated stress state variables, i.e. vertical net stress $\left(\sigma_{n}-u_{a}\right)$ and matric suction $\left(u_{a}-u_{w}\right)$ [13]. The retention curve (Figure 4) and effective shear strength parameters interpreted from shear test S2 (Figure 9, Figure 11) were used for the prediction, applying "Vanapalli's $1^{\text {st }}$ method" [14] (Eq. 1).

$$
\tau_{f}=\left[c^{\prime}+\left(\sigma_{n}-u_{a}\right) \tan \varphi\right]+\left(u_{a}-u_{w}\right)\left[\Theta^{\kappa} \tan \varphi^{\prime}\right]
$$

in which $\left(\sigma_{n}-u_{a}\right)$ is net normal stress on the failure plane at failure, normalized water content $\Theta$ is given by $\Theta=\theta / \theta_{s}$ where $\theta$ and $\theta_{s}$ are volumetric and saturated volumetric water contents, respectively, $\kappa$ is an exponent accounting for the relation between normalized water content and the normalized area of water in the pores, $a_{w}$, where $a_{w}=\Theta^{k}$. The normalized water content is a function of suction and of the retention curve (Figure 4). Good correlation between experimental results and predicted shear strength for a value of $\kappa$ equal to 2.2 was found for shear tests on a compacted glacial till [14].

A comparison between measured and predicted shear strength gives good agreement (Figure 13). This is not surprising, since the effective friction angle $\varphi^{\prime}$ was interpreted from the same data set. Vertical net stress is relatively high and dominates the total value of measured shear strength, in particular for test Sand S2.

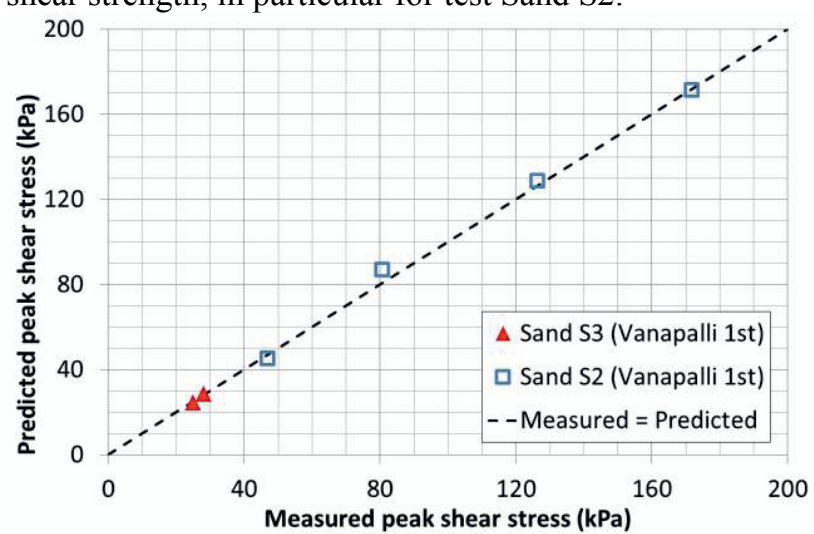

Figure 13 Comparison between measured and predicted shear strength for tests Sand S2 and Sand S3 using prediction method "Vanapalli $1^{\text {st" }}[14]$.

For evaluation of suction effects on unsaturated shear strength, measured shear strength data translated to the zero vertical net stress plane (Figure 11) were compared with predictions applying Eq. (1) (Figure 14).

The predicted shear stress has a good match with measured peak shear stress (translated to zero vertical net stress) at suction equal to $7 \mathrm{kPa}$ (Figure 14). Applied suction is slightly higher than the air entry value of $5 \mathrm{kPa}$ (Figure 4). The predicted shear strength is non-linear below the air entry value, but no test data are available for this suction range.

The predicted non-linearity of the shear strength curve in Figure 14 is a result of the saturation rate being lower 
than unity below the air entry value (Figure 4). The tangential definition of the air entry value [15] characterizes the retention curve in a consistent way, but the air entry value generally does not correspond with the value where drainage of water from the soil actually starts. From an initial steep increase of shear strength as suction increases at a high saturation rate, the inclination of the predicted shear strength curve drops gradually as water is drained from the soil. The predicted peak shear strength is located close to the peak shear stress from the second load step in shear test Sand S3, for which the suction was $7 \mathrm{kPa}$. Increasing suction further, the predicted shear stress drops gradually to a value just above the effective cohesion. This means that increased suction above some limiting value gives practically no contribution to the shear strength. Test Sand S2 gives some confirmation of this effect; considering either the average value of the four load steps of test Sand S2 or each of the four data points (translated to zero vertical net stress), they all lie below predicted and measured peak shear strength for a suction value of $7 \mathrm{kPa}$ (Figure 14).

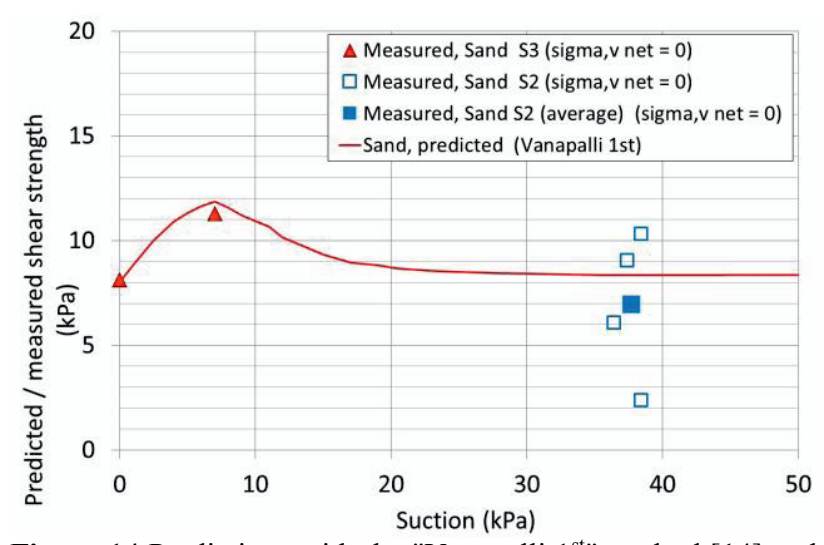

Figure 14 Predictions with the "Vanapalli $1^{\text {st" }}$ method [14] and measured shear strength versus suction for shear tests on sand, translated to zero vertical net stress. Average point of four test steps at constant suction $(37-38 \mathrm{kPa})$ included for test Sand S2.

The ultimate shear strength for large suction (above suction corresponding to residual water content, Figure 4) seems to approach the effective cohesion, which on the other hand is equal to the shear strength for zero suction (and zero vertical net stress). The highest shear strength along the suction axis is reached for some suction value depending directly on the shape of the retention curve; in general, the maximum shear strength coincides with the maximum of the product $\left(u_{a}-u_{w}\right) \Theta^{\kappa}[14]$

For evaluation of slope stability, the results above indicate that the shear strength, and hence the slope stability, will be about the same for completely dry and for fully saturated conditions. In both cases, there is no effect of suction to stabilize the soil, and the shear strength contribution as a function of suction is reduced to the value of the effective cohesion. In this case, the low suction range $(0-15 \mathrm{kPa})$ in fact will give the best theoretical stability. This however holds only as long as pore-water pressure remains negative (i.e. as long as there is soil suction in situ). If a soil is close to full saturation, positive pore-water pressures may quickly develop as a result of infiltration, which will then act to reduce also the shear strength contribution from the other stress state variable, i.e. vertical net stress, since $\sigma_{n}-u_{a}$ for saturated soil will be equal to $\sigma_{n}-u_{w}$ or Terzaghi's effective stress. The stabilizing effect of suction on slope stability will consequently be reversed with saturation. Hence, for slope stability evaluations, the dry side of the peak is still a safer place than the wet side, although the theoretical suction effect on stability may be marginal, at least for the sandy soil presented herein.

\section{References}

1. $\square$ C. Jaedicke, A. Kleven, Hydr. Proc. 22 (2008)

2. $\square$ F. Sandersen, S. Bakkehøi, E. Hestnes, K. Lied, Proc. 7th ISL (1996)

3. G. J. Meijer, A. G. Bengough, J. A. Knappett, K. W. Loades, B. C. Nicoll, Proc. XVI ECSMGE 4 (2015)

4. $\square$ H. Heyerdahl, T. Pabst (in prep.)

5. $\square$ H. Heyerdahl, in prep.

6. $\square$ V. Escario, J. Saez, Geot. 36, 3 (1986)

7. $\square$ J.W. Hilf, US Bureau of Reclamation, Tech. memo., 654 (1956)

8. $\square$ D. G. Fredlund, H. Rahardjo, J. K. M. Gan, Proc. 6th Int. Conf. On Expansive Soils 1 (1987)

9. I. B. Donald, Proc. $2^{\text {nd }}$ Australia-New Zeeland Conf. Soil Mech. Found Eng. (1956)

10. $\square$ A. Tarantino, Mech. of unsaturated geomaterials (2010)

11. E. E. Alonso, A. Gens, A. Josa, Geot. 40, 3 (1990)

12. E. Derbyshire, T. A. Dijkstra, I. J. Smalley, Y. Li, Quat. Int. 24 (1994)

13. D. G. Fredlund, N. R. Morgenstern, J. of the Geot. Eng. Div., ASCE 103, GT5 (1977)

14. S. K.Vanapalli, D. G. Fredlund, D. E. Pufahl, A. W. Clifton, Can. Geot. J. 33, 3 (1996)

15. D. G. Fredlund, H. Rahardjo, Soil mechanics for unsaturated soils (1993)

Table 3. Summary of volumetric properties for tested sand specimens

\begin{tabular}{|c|c|c|c|c|c|c|c|c|c|c|c|}
\hline Sample & Specimen & Test & Depth & $\gamma_{d}$ & $n$ & $e$ & $w_{\text {in situ }}$ & $S_{r, \text { in situ }}$ & $\gamma_{\text {in situ }}$ & $w_{\text {sat }}$ & $\gamma_{\text {sat }}$ \\
\hline ID & ID & & $\mathrm{m}$ & $\mathrm{kN} / \mathrm{m}^{3}$ & $\%$ & - & $\%$ & - & $\mathrm{kN} / \mathrm{m}^{3}$ & $\%$ & $\mathrm{kN} / \mathrm{m}^{3}$ \\
\hline \multirow{3}{*}{ A1 } & Sand S1 & \multirow{3}{*}{ Shear box } & $0.56-0.58$ & 13.80 & 46.9 & 0.88 & 15.81 & 0.47 & 15.98 & 33.36 & 18.40 \\
\hline & Sand S2 & & $0.61-0.63$ & 14.25 & 45.2 & 0.82 & 12.81 & 0.41 & 16.08 & 31.10 & 18.68 \\
\hline & Sand S3 & & $0.65-0.67$ & 14.50 & 44.2 & 0.79 & 12.59 & 0.42 & 16.32 & 29.92 & 18.83 \\
\hline $\mathrm{P} 4$ & Sand O1 & Odometer & $0.24-0.28$ & 15.48 & 40.5 & 0.68 & - & - & - & 25.64 & 19.44 \\
\hline
\end{tabular}

